\title{
Spontaneous Rupture of a Hepatic Adenoma: Diagnostic Nuances and the Necessity of Followup
}

\author{
Preston F. Ashby ${ }^{1}$, Chelsea Alfafara ${ }^{2}$, Albert Amini ${ }^{3}$, Richard Amini ${ }^{4}$
}

1. Department of Surgery, Arizona College of Osteopathic Medicine 2. College of Medicine, University of Arizona 3. Arizona Premier Surgery, Chandler Regional Hospital 4. Department of Emergency Medicine, University of Arizona

$\square$ Corresponding author: Richard Amini, richardamini@gmail.com

Disclosures can be found in Additional Information at the end of the article

\section{Abstract}

We present the case of a young female on oral contraceptives (OCs) who was diagnosed with focal nodular hyperplasia (FNH) and remained on oral contraceptives. Months later, the patient presented with acute abdominal pain and intratumoral hemorrhage in the liver. The patient was taken to the operating room (OR) and was diagnosed with a ruptured hepatic adenoma (HA). We review the key diagnostic features of FNH and HA, the different management guidelines including use of OCs, and potential surgical indications. HA compared to FNH has a significantly higher rate of sequelae despite being a benign lesion, thus providers must accurately distinguish between the two diagnoses to prevent potential morbidity and mortality.

Categories: Emergency Medicine, Radiology, General Surgery

Keywords: hepatic hemangioma, focal nodular hyperplasia, hepatic adenoma

\section{Introduction}

After hepatic hemangioma, focal nodular hyperplasia (FNH) and hepatic adenoma (HA) are the second and third most common benign liver neoplasms, respectively. Both tumors are typically asymptomatic and are usually discovered incidentally on imaging. HA is strongly associated with exposure to estrogens, particularly estrogen-containing oral contraceptives (OCs) [1]. Overall, up to $30 \%$ of HA tumors are associated with rupture or hemorrhage, and this risk is highest in patients with hormone use and in patients with larger tumors $(>5 \mathrm{~cm})$ [2]. If bleeding is severe, emergent surgery must be performed, which carries a $5-10 \%$ mortality rate. This is significantly higher than elective tumor resections which have a mortality rate of $1 \%$. Malignant transformation of HAs has been documented as high as 5\% [3], whereas FNH has no known malignant potential and few, if any, complications.

\section{Case Presentation}

A 31-year-old Caucasian female presented to the emergency department with acute right upper quadrant (RUQ) abdominal pain over the past day. The patient described her pain as constant, sharp, and burning, with radiation to the back. The patient also complained of nausea and nonbloody, non-bilious emesis. Her past medical history was significant for hypertension and a liver mass consistent with FNH that was incidentally noted on abdominal computed tomography (CT) over a year ago (Figure 1). 


\section{Cureus}

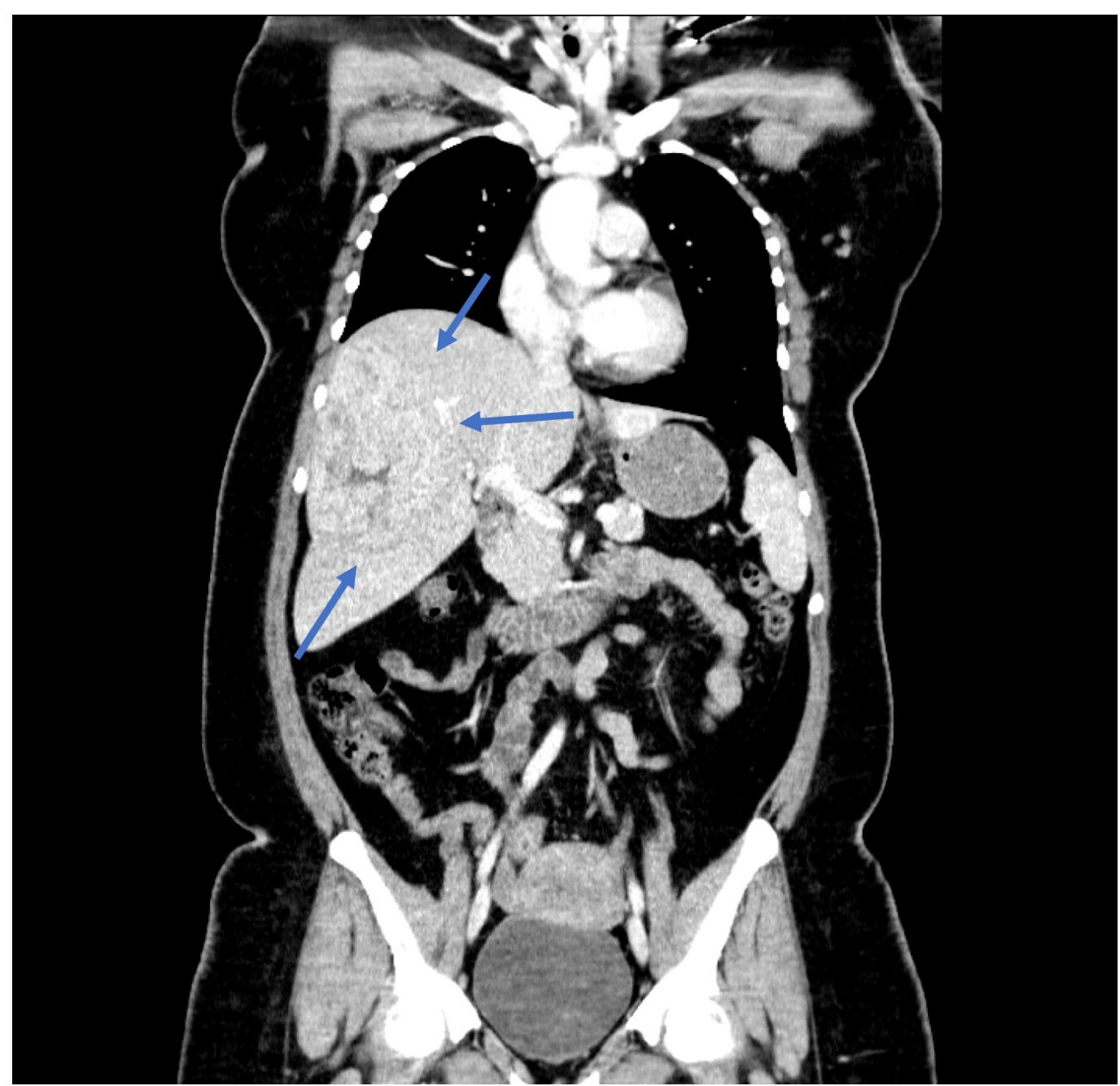

\section{FIGURE 1: Computed tomography one year prior to presentation.}

Computed tomography demonstrates a $12.6 \mathrm{~cm} \times 12.1 \mathrm{~cm} \times 8.6 \mathrm{~cm}$ right liver mass with central stellate scar present, consistent with focal nodular hyperplasia (FNH). Followup with nonemergent outpatient magnetic resonance imaging (MRI) recommended.

Although the patient was given instructions to follow up with her primary care physician (PCP) to review the liver mass findings and potentially receive outpatient magnetic resonance imaging (MRI), the patient did not follow up. The patient's relevant medications were OC use for the past six years. On physical examination, there was hepatomegaly and significant tenderness to palpation over the RUQ. The patient did not exhibit rebound tenderness, guarding or Murphy's sign.

Initial work-up included a negative pregnancy test, elevated liver enzymes with an Alkaline phosphatase level of $116 \mathrm{IU} / \mathrm{L}$, Aspartate Aminotransferase (AST) of $160 \mathrm{IU} / \mathrm{L}$, Alanine Aminotransferase (ALT) of $281 \mathrm{IU} / \mathrm{L}$, and total bilirubin of $0.5 \mathrm{mg} / \mathrm{dL}$. White blood cell count (WBC) was slightly elevated at 12,000 per microliter and her hemoglobin level was $11.5 \mathrm{~g} / \mathrm{dL}$. The international normalized ratio (INR) was 1.1 and Creatinine was $0.77 \mathrm{mg} / \mathrm{dL}$. CT scan of the abdomen with contrast demonstrated the same large heterogeneous mass in the right lobe of the liver (Figure 2) without acute pathology to explain the patient's pain. RUQ ultrasound demonstrated the same findings and there were no signs of acute cholecystitis. 


\section{Cureus}

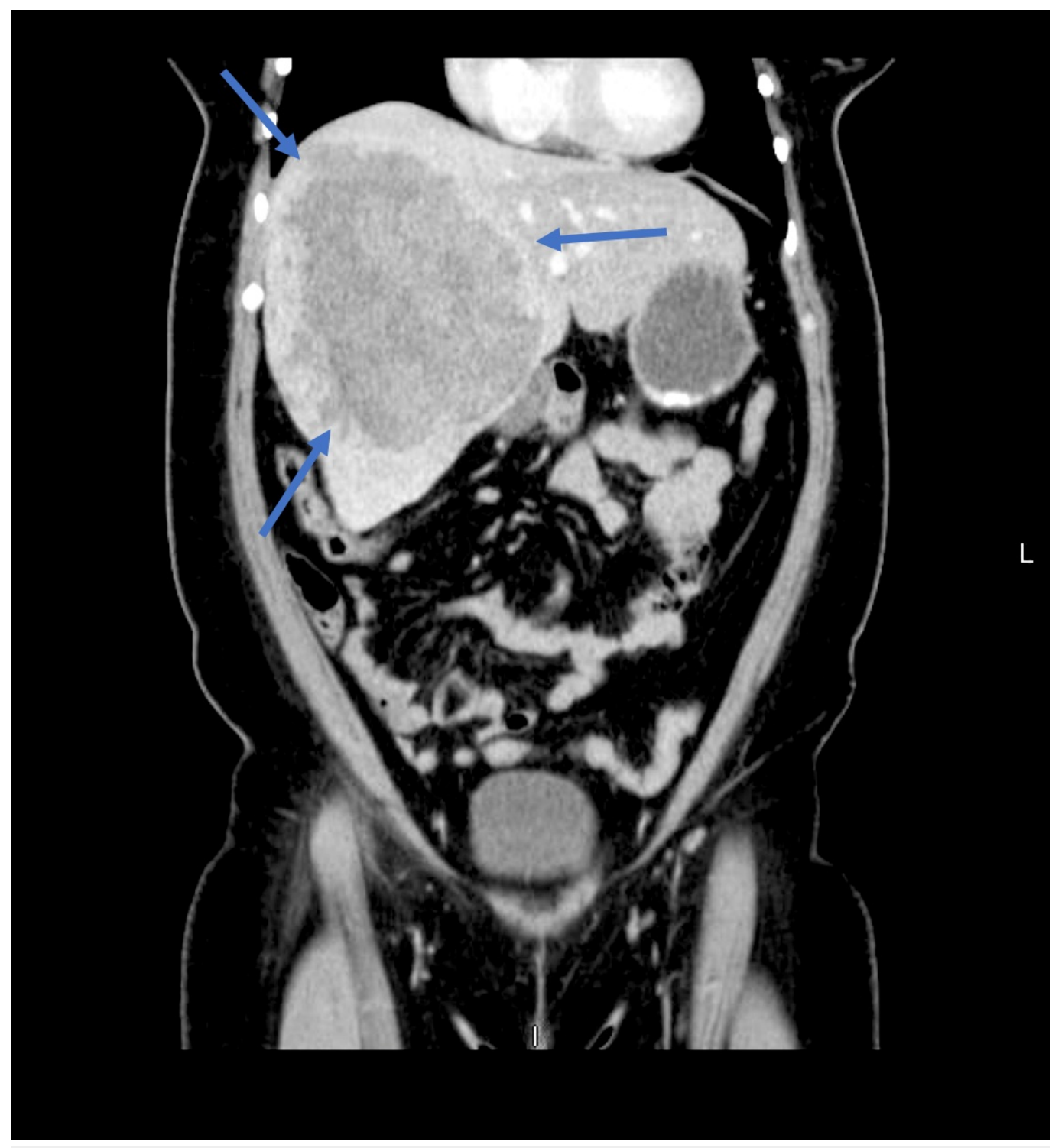

FIGURE 2: Computed tomography on the day of presentation.

Computed tomography demonstrating a $16 \mathrm{~cm} \times 13 \mathrm{~cm} \times 13 \mathrm{~cm}$ right liver mass with central stellate scar consistent with focal nodular hyperplasia (FNH).

The emergency physician admitted the patient for intractable pain and hematology/oncology was consulted as a result of the liver lesion. On the subsequent day, the patient's pain continued and repeat blood test demonstrated a drop in hemoglobin level to $8.1 \mathrm{~g} / \mathrm{dL}$. Concern for internal bleeding led physicians to order an MRI of the abdomen with and without contrast, which demonstrated a $15.3 \mathrm{~cm} \times 12.5 \mathrm{~cm}$ x $14.1 \mathrm{~cm}$ heterogeneous mass straddling the right and left lobe of the liver. There was heterogeneous $\mathrm{T} 1$ and $\mathrm{T} 2$ hyperintensity throughout the entire mass, and mild peripheral enhancement consistent with hemorrhage. In addition, three smaller lesions with $\mathrm{T} 1$ hyperintensity, about $2 \mathrm{~cm}$ in size, were noted adjacent to the larger mass (Figure 3). 


\section{Cureus}

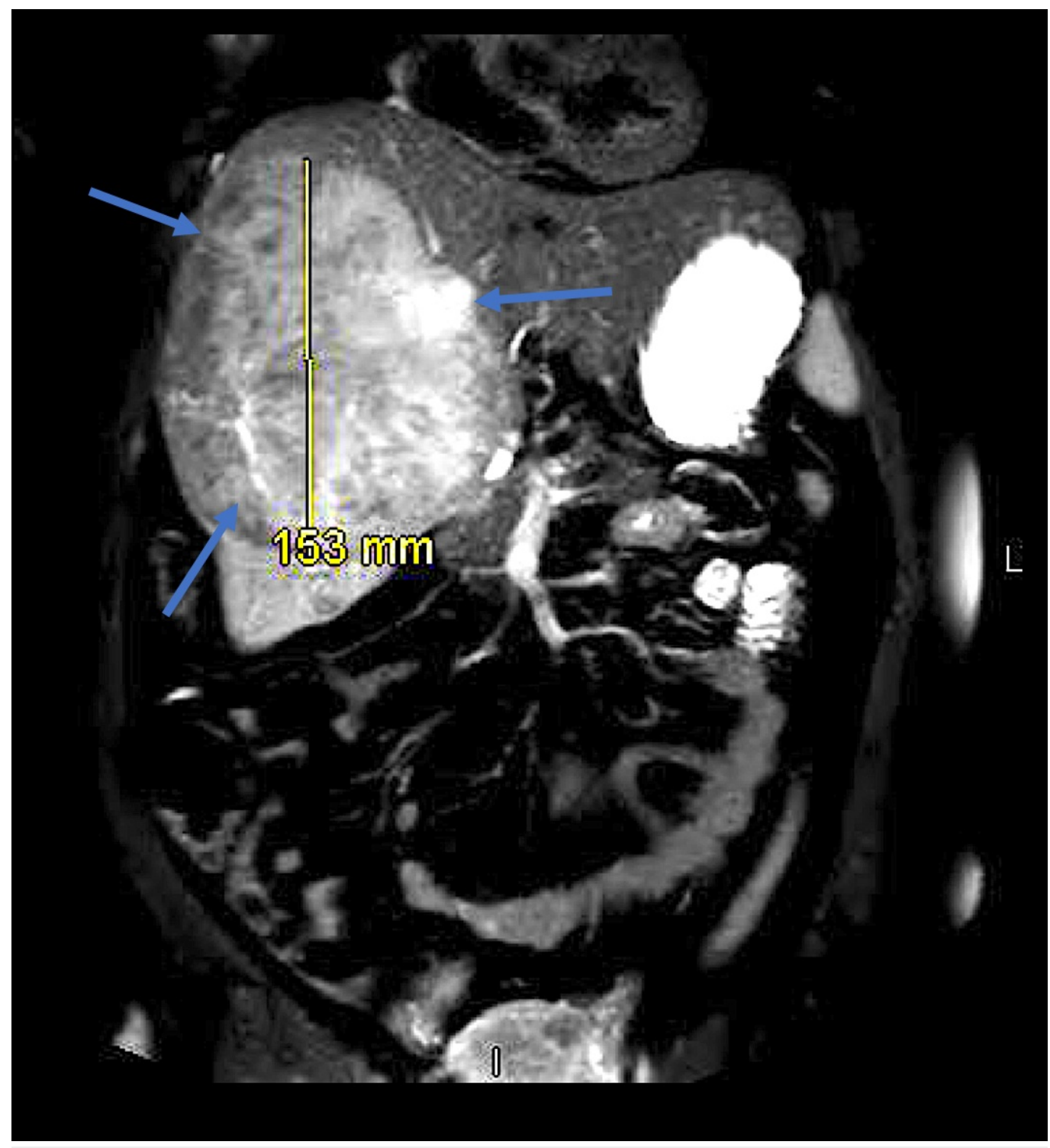

FIGURE 3: Magnetic resonance imaging of the abdomen.

The magnetic resonance imaging (MRI) of the abdomen demonstrated a $15.3 \mathrm{~cm} \times 12.5 \mathrm{~cm} \mathrm{x}$ $14.1 \mathrm{~cm}$ heterogeneous mass straddling the right and left lobe of the liver. There was also peripheral enhancement consistent with hemorrhage.

Interventional radiology performed a biopsy of the large liver mass. Histopathology results from the biopsy revealed hepatocellular neoplasm with extensive necrosis. CD34 stain showed increased vascularity. Due to the history of OC use and the characteristics of the liver mass found on imaging, the leading differentials were HA or a well differentiated hepatocellular carcinoma (HCC) or FNH.

The patient underwent a laparoscopic-assisted extended right hepatectomy including parts of segment 4 and 1 (Figure 4 ). 


\section{Cureus}

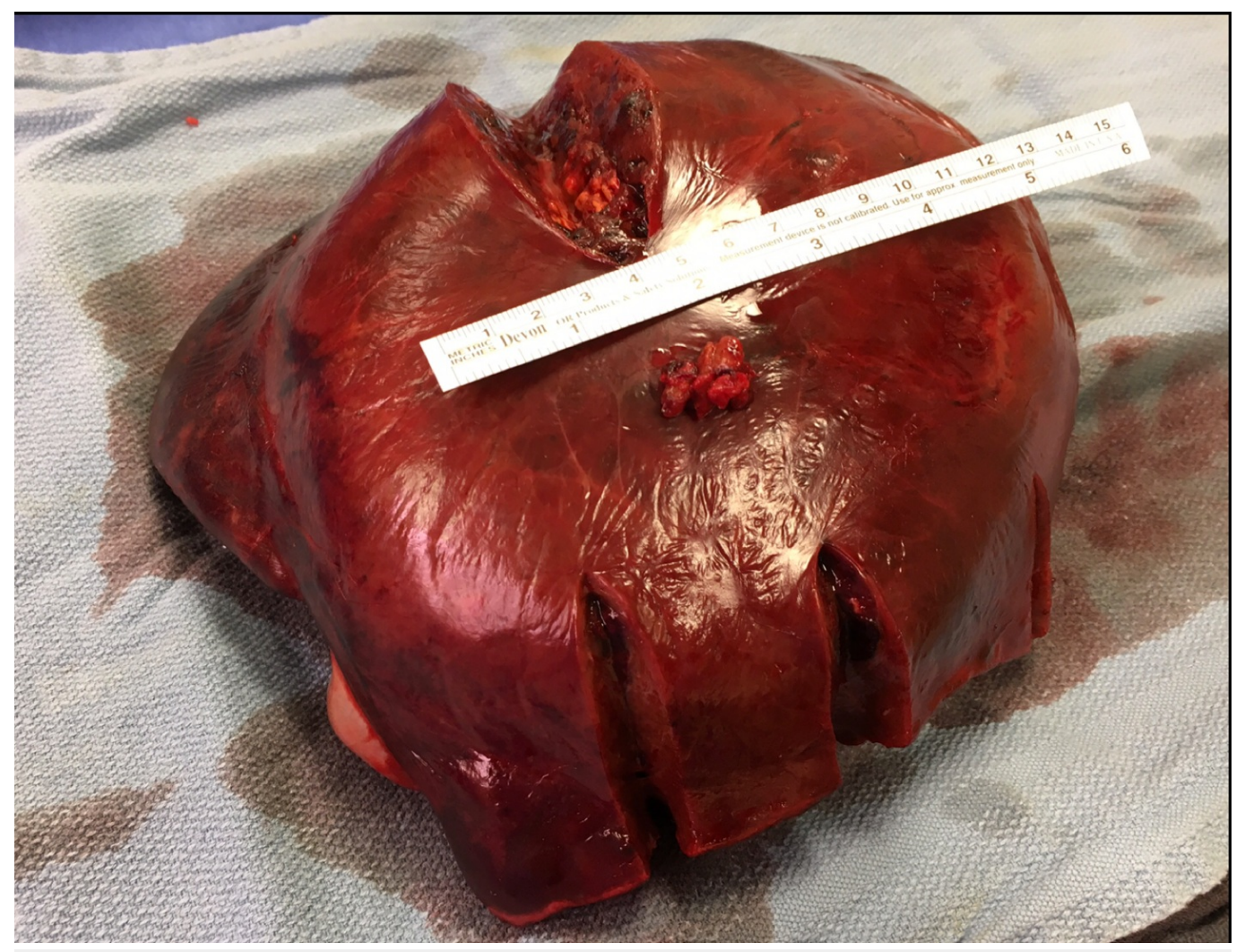

\section{FIGURE 4: Postoperative image of the resected hepatic}

adenoma.

The patient underwent a laparoscopic-assisted extended right hepatectomy including parts of segment 4 and 1.

There were no intraoperative complications, she recovered well, and was discharged on postoperative day 4. Her postoperative labs demonstrated improved liver function enzymes and normal WBC. The histopathology of the surgical specimen was identified as a hepatic adenoma with surrounding hemorrhage and negative resection margins. Beta-catenin was negative which means the patient is at a lower risk for malignant transformation.

The patient returned to the surgery clinic for postoperative followup. Her repeat liver function tests decreased to an AST of $34 \mathrm{IU} / \mathrm{L}$ and an ALT of $87 \mathrm{IU} / \mathrm{L}$. Her WBC normalized to 6,700 per microliter. She had no peri-operative or post-operative complications. She plans to schedule an appointment with the gynecologist for alternative contraceptive options.

\section{Discussion}

FNH is a benign neoplasm that affects all ages and preferentially affects women over men (89:1). Currently, it is the second most common cause of benign hepatic tumors in adults behind hepatic hemangiomas [3]. Although the pathophysiology of FNH is not fully understood, a proposed mechanism is that the tumor arises from locally disturbed blood flow, which subsequently causes a hyperplastic, polyclonal response in normal hepatocytes as a result of either hypoxia or hyperperfusion [3]. Though the role of OCs in FNH is not clear, OCs may contribute to the growth of the tumor [4].

Histologically, FNH is described as a focal form of cirrhosis with a central fibrous scar, ductular 
proliferation, and malformed vessels. The central fibrous scar may manifest on CT scan or MRI as a central stellate scar, which is pathognomonic for FNH. Other imaging characteristics typically include a mass less than $5 \mathrm{~cm}$ in size [5], lobulated, but well demarcated, and homogeneity with slight hypo- or isoattenuation compared to the surrounding liver [5]. MRI will demonstrate hypo- or isoattenuation on T1 weighted images, but will show hyper- or isoattenuation on T2 weighted images [5]. MRI stands to be the most sensitive (70\%) and specific (98-100\%) diagnostic imaging technique. Furthermore, it is preferred over CT so as to avoid radiation in women of childbearing age [3]. Though CT scan with contrast is a reasonable alternative to MRI, there can be atypical characteristics that make the distinction between FNH and HA difficult [6]. Lastly, ultrasound is not a sufficient imaging modality to distinguish between FNH and HA; however, ultrasound with contrast has shown promise as an accurate and inexpensive imaging modality in the diagnosis of FNH [7]. When results of an abdominal MRI/CT are inconclusive, the patient may then be referred for a liver biopsy.

FNH is typically asymptomatic; the lesion is usually found incidentally, and only $12-13 \%$ of patients reporting abnormal serum liver tests. Rare symptoms include palpable abdominal mass (2-4\%), hepatomegaly ( $<1 \%)$, and fever $(<1 \%)$ [3]. When asymptomatic, FNH does not usually require surgical resection due to a very low risk of complications. The American College of Gastroenterology (ACG) recommends annual ultrasonography to monitor the lesion if the patient decides to continue OCs. In the absence of OCs and a firm diagnosis of FNH, the patient requires no further followup. Furthermore, if the patient is asymptomatic, surgery is not recommended [8].

Behind hepatic hemangioma and FNH, HA is the third most common cause of benign liver neoplasms and is found almost exclusively in women between the second to fifth decade of life. Since the 1970s, with the advent of OCs, the incidence of HA in young women has increased [9]. A case-control study conducted by Rooks, et al., estimates the risk of HA for longterm users of low-potency OCs correlates with an annual incidence of 3.4 per 100,000 [1]. Although the exact disease mechanism is largely unknown, HAs association with young women on oral contraceptives may suggest an estrogen-induced pathologic mechanism. Furthermore, there is convincing evidence between dose and duration of OCs with incidence of HA, adenoma size, and malignant transformation risk [1]. Other less-documented associations to HA are the use of anabolic androgenic steroids by bodybuilders and glycogen storage disease [3].

HAs are reported to be solitary lesions (70-80\% of cases), which lack an obvious fibrous capsule on imaging. Histologically, these neoplasms are characterized by the presence of liver cell plates in the absence of bile ducts and fibrosis [3]. Aberrant vascular structures are extensive within the sinusoids supplied by the peripheral arterial system but lacking in supply by the portal venous system. Unlike FNH, hepatic adenomas do not feature bile ductules or other portal tract elements or fibrosis [3]. Imaging modalities used to diagnose HA are multiphase CT and MRI. Liver biopsy following inconclusive imaging studies remains controversial due to the increased risk of bleeding and hemorrhage [3].

Like those with FNH, a majority of patients with $\mathrm{HA}$ are often asymptomatic with up to $7 \%$ of cases reporting abnormal serum liver tests. Thirty to $40 \%$ of patients report abdominal discomfort and $2-4 \%$ have a palpable abdominal mass [3]. These patients, however, are more likely to present with acute abdominal pain after tumor rupture or hemorrhage. Up to a 30\% incidence of spontaneous bleeding is reported and $5 \%$ progression to hepatocellular carcinoma in HA cases, and thus, surgical resection is the preferred choice of treatment. If a suspected HA is less than $5 \mathrm{~cm}$ in size, it can be monitored without surgery. However, followup imaging is recommended. Repeat CT or MRI at 6-12 month intervals is required and duration of followup depends on the stability of the HA over time [8]. Cessation of OCs, including progesterone only OCs, is recommended in all patients with HA [3, 9]. Alternative contraception is limited to copper intrauterine device, barrier methods, or more permanent methods such as tubal ligation, 


\section{Cureus}

vasectomy, or hysterectomy.

Various epidemiologic, histologic, diagnostic, and clinical management differences exist between FNA and HA, and these differences are highlighted in Figure 5.

\begin{tabular}{|c|c|c|}
\hline & Focal Nodular Hyperplasia & Hepatic Adenoma \\
\hline Epidemiology & $\begin{array}{l}\text { All ages [3] } \\
8-9: 1 \text { female to male ratio [3] } \\
\text { No correlation with estrogen oral } \\
\text { contraceptives }\end{array}$ & $\begin{array}{l}2^{\text {nd }} \text { to } 5^{\text {th }} \text { decade [3] } \\
\text { Nearly exclusively female [3] } \\
\text { Strong correlation with estrogen } \\
\text { oral contraceptives [1] }\end{array}$ \\
\hline Clinical Presentation & Asymptomatic [3] & $\begin{array}{l}\text { Abdominal pain or asymptomatic } \\
{[3]}\end{array}$ \\
\hline Laboratory Tests & $\begin{array}{l}\text { Normal or non-remarkable } \\
\text { Normal AFP [3] }\end{array}$ & $\begin{array}{l}\text { Normal or non-remarkable } \\
\text { Normal AFP [3] }\end{array}$ \\
\hline Histopathology & $\begin{array}{l}\text { Central scar } \\
\text { Ductular reaction } \\
\text { Fibrosis [3] }\end{array}$ & $\begin{array}{l}\text { Liver cell plates } \\
\text { No bile ducts } \\
\text { No fibrosis [3] }\end{array}$ \\
\hline Differences on CT & $\begin{array}{l}\text { Central stellate scar commonly } \\
\text { seen } \\
\begin{array}{l}\text { Homogenously hypervascular } \\
\text { during arterial phase }\end{array} \\
\begin{array}{l}\text { Invisible or isodense during } \\
\text { venous phase }\end{array} \\
\begin{array}{l}\text { Paucity of internal neovascularity } \\
\text { but prominent feeding vessel from } \\
\text { hepatic artery lesions }[5]\end{array} \\
\end{array}$ & $\begin{array}{l}\text { Central stellate scar rarely seen } \\
\text { Heterogenously hypervascular } \\
\text { during arterial phase } \\
\text { Variable during venous phase } \\
\text { Perfusion of neovascularity [5] }\end{array}$ \\
\hline Differences on MRI & $\begin{array}{l}\text { Iso- or hypointensity on T1- } \\
\text { weighted image } \\
\text { Slight hyper- or isointensity with } \\
\text { presence of hyperintense central } \\
\text { scar on T2-weighted images } \\
\text { Homogenously hypervascular } \\
\text { during arterial phase } \\
\text { Isodense during venous phase } \\
\begin{array}{l}\text { Central scar hyperintensity with } \\
\text { delayed phase imaging [3] }\end{array}\end{array}$ & $\begin{array}{l}\text { Mostly hyperintense on T1- } \\
\text { weighted image. Occasionally } \\
\text { iso- or hypointense. } \\
\text { Heterogenous with combination } \\
\text { of hyper- and hypointensity on } \\
\text { T2-weighted images } \\
\text { Enhancement on arterial phase }\end{array}$ \\
\hline Management & Expectant management [3] & $\begin{array}{l}\text { Withdrawal of OC treatment [3, } \\
5] \\
\text { Surgical resection if larger than } 5 \\
\mathrm{~cm}[3] \\
\text { Serial imaging and follow up in 6- } \\
12 \text { month intervals for lesions less } \\
\text { than } 5 \mathrm{~cm}[8]\end{array}$ \\
\hline Potential complications & None [3] & $\begin{array}{l}\text { Risk of rupture as high as } 30 \% \text { [3] } \\
\text { Malignant transformation to } \\
\text { hepatocellular carcinoma as high } \\
\text { as 5\% [3] }\end{array}$ \\
\hline
\end{tabular}

FIGURE 5: Differentiating focal nodular hyperplasia from hepatic adenoma.

In our case, the patient was diagnosed with an FNH based on CT imaging. An MRI was 
recommended for followup, but the patient did not follow up and did not receive additional imaging. As discussed, atypical lesions may be difficult to diagnose on CT and thus require MRI. A diagnosis of HA could have led to earlier termination of her OCs. Although unlikely to have prevented surgery, due to the large size of the tumor, appropriate followup and imaging may have led to the reduction in the size of the liver resection and higher likelihood of complete laparoscopic resection.

\section{Conclusions}

Although HA and FNH are common hepatic lesions with numerous similaries, clinicians should be aware of the diagnostic differences, preferred imaging modalities, and clinical management differences. Clinicians should have discussions with their patients with regard to the use of OCs, the necessity of close outpatient followup, choice of imaging modalities, and the potential need for surgical consultation.

\section{Additional Information Disclosures}

Human subjects: Consent was obtained by all participants in this study. Conflicts of interest: In compliance with the ICMJE uniform disclosure form, all authors declare the following: Payment/services info: All authors have declared that no financial support was received from any organization for the submitted work. Financial relationships: All authors have declared that they have no financial relationships at present or within the previous three years with any organizations that might have an interest in the submitted work. Other relationships: All authors have declared that there are no other relationships or activities that could appear to have influenced the submitted work.

\section{References}

1. Edmondson HA, Henderson B, Benton B: Liver-cell adenomas associated with use of oral contraceptives. N Engl J Med. 1976, 294:470-472. 10.1056/NEJM197602262940904

2. van Aalten SM, de Man RA, IJzermans JN, et al.: Systematic review of haemorrhage and rupture of hepatocellular adenomas. Br J Surg. 2012, 99:911-916. 10.1002/bjs.8762

3. Maillette de Buy Wenniger L, Terpstra V, Beuers U: Focal nodular hyperplasia and hepatic adenoma: epidemiology and pathology. Dig Surg. 2010, 27:24-31. 10.1159/000268404

4. Sarma A, Shaaban AM, Heilbrun ME, et al.: Two cases of near-complete regression of focal nodular hyperplasia of the liver: case reports and review of the literature. Radiol Case Rep. 2012, 7:681. 10.2484/rcr.v7i3.681

5. Mortele KJ, Praet M, Van Vlierberghe H, et al.: CT and MR imaging findings in focal nodular hyperplasia of the liver: radiologic-pathologic correlation. AJR Am J Roentgenol. 2000, 175:687-692. 10.2214/ajr.175.3.1750687

6. Hussain SM, Terkivatan T, Zondervan PE, et al.: Focal nodular hyperplasia: findings at stateof-the-art MR imaging, US, CT, and pathologic analysis. Radiographics. 2004, 24:3-17. 10.1148/rg.241035050

7. Kim TK, Jang H, Burns PN, et al.: Focal nodular hyperplasia and hepatic adenoma: differentiation with low-mechanical-index contrast-enhanced sonography. AJR Am J Roentgenol. 2008, 190:58-66. 10.2214/AJR.07.2493

8. Marrero JA, Ahn J, Reddy KR, et al.: ACG clinical guideline: the diagnosis and management of focal liver lesions. Am J Gastroenterol. 2014, 109:1328-1347. 10.1038/ajg.2014.213

9. Herman P, Pugliese V, Machado MA, et al.: Hepatic adenoma and focal nodular hyperplasia: differential diagnosis and treatment. World J Surg. 2000, 24:372-376. 10.1007/s002689910059 